\title{
Investigator Recruitment Process
}

National Cancer Institute

\section{Source}

National Cancer Institute. Investigator Recruitment Process. NCI Thesaurus. Code C142590.

A set of actions used by sponsors to identify and select clinical assessors to serve in a clinical study. 